\title{
Relaxation-induced contraction of smooth muscle surrounding hamster ovarian follicles*
}

\author{
D. A. Self, A. R. Koch and P. C. Schroeder \\ Program in Zoophysiology, Department of Zoology, Washington State University, Pullman, \\ WA 99164, USA
}

\begin{abstract}
Summary. Changes in intrafollicular pressure and follicular diameter resulting from injecting or withdrawing fluid from the antrum were measured in preovulatory follicles and used as an assay for changes in tension in the follicular wall by applying the Laplace relationship for thin-walled spheres. Passive length-tension curves were constructed from pressure-volume measurements to establish baseline wall stiffness. Any subsequent change in pressure could then be compared to the length-tension curves to evaluate whether it arose from active tension development or from passive stretch. When intact follicles (1-2 h before ovulation) were subjected to release of passive stretch, they exhibited a contractile response that lasted $15 \mathrm{sec}-2 \mathrm{~min}$ and was characterized by cyclic increases and decreases in tension, with a period of 1 cycle every $2-3 \mathrm{sec}$. The probability of activating a response in the tissue was most strongly correlated with the rate of release of passive stretch. Intrafollicular pressures generated during active contractile responses sometimes reached $80 \mathrm{mmHg}(10.64 \mathrm{mPa})$, corresponding to a wall tension of 5332 dynes $/ \mathrm{cm}(5 \cdot 332 \mathrm{~N} / \mathrm{m}$ ) (for a $1 \mathrm{~mm}$ follicle) and were clearly well above the passive length-tension curves. Passive stretching of the follicular wall during a contractile response to 5-hydroxytryptamine stimulation resulted in large reductions in active wall tension for the duration of the stretch. These results are consistent with a stretch-activated inhibition of contractile events.
\end{abstract}

Keywords: ovulation; Laplace formula; follicle; smooth muscle

\section{Introduction}

Evidence for constriction of the wall of intact preovulatory hamster follicles has been provided through the use of transmission electron microscopy by Talbot \& Chacon (1982). That this event plays a role in ovulation has been suggested by Martin \& Talbot (1981b), who demonstrated that ovulation in hamsters could be inhibited by a variety of drugs known to inhibit smooth muscle contraction.

Recently, through the use of a new monoclonal antibody to muscle actin (HHF35), we have shown that both of the muscle-specific isotypes of actin (alpha and gamma) are present in the theca externa of hamster follicles. Additionally, cells from this layer, identified as smooth muscle by their reactivity with HHF35 when grown in culture, contract in response to a calcium influx created by the ionophore A23187 (Self et al., 1988).

There exists extensive adrenergic innervation of the theca externa (Stefanson et al., 1981), which may play a role in the ovulatory process by affecting contractility of the follicular wall (Kannisto et al., 1985; Spicer, 1986). However, ovulation has been demonstrated to occur in isolated, perfused rabbit ovaries (Lofman et al., 1982) and in denervated rat ovaries (Wylie et al., 1985). Further,

*Reprint requests to: Alan R. Koch. 
5-hydroxytryptamine causes contraction of hamster follicular smooth muscle (Talbot \& Schroeder, 1982) and may be released in the ovary by aggregating platelets before ovulation (Espey, 1980).

These findings suggest that follicular contraction during ovulation may be mediated by both pharmacological and mechanical influences. We have evaluated the impact of changes in passive stretch of the follicular wall on contractility and have attempted to place the role of such an influence within the physiological context of other previously established parameters of the ovulatory process.

\section{Materials and Methods}

Animals. Sexually mature female golden hamsters (Mesocricetus auratus) maintained in an air-conditioned room, with $12 \mathrm{~h}$ light per day (23:00-11:00 h), and allowed food and water ad libitum were used. Oestrous cycles were monitored using the criteria (external vaginal phenomena) of Orsini (1961). Superovulation was induced by injecting 25 i.u. pregnant mares serum gonadotrophin (PMSG: Sigma, St Louis, MO, USA) on the morning of vaginal discharge (Day 1). Ovulation was anticipated to occur on the afternoon of Day 4, 12-13 h after the mid-point of the $12 \mathrm{~h}$ light period on that day (Reuter et al., 1970; Bast \& Greenwald, 1974). In some experiments, 25 i.u. human chorionic gonadotrophin (hCG: Sigma) were injected on the evening of Day 3, to control the time of ovulation (estimated to occur 13-14 h later). On the afternoon of Day 4 (1-2 h before the time of expected ovulation), the animals were anaesthetized by intramuscular injection of ketamine $\mathrm{HCl}(250 \mathrm{mg} / \mathrm{kg}$ : Parke-Davis, Morris Plains, NJ, USA).

Surgeries. In preparation for the experiments, a cannula was inserted into the trachea and gallamine triethiodide ( $20 \mathrm{mg} / \mathrm{kg}$ : Davis \& Geck, Pearl River, NY, USA) was administered directly into the external jugular vein. Paralysis was necessary to prevent disturbances in the intrafollicular pressure recordings caused by contraction of the respiratory musculature. The tracheal cannula was then connected to a small animal respirator that supplied $100 \%$ oxygen. Heart rate was continually monitored from a limb-lead electrocardiogram. The ovaries were exposed by a dorsal incision, just lateral to the vertebrae at the level of L-2. The uteri, ovaries and oviducts were pulled as a unit through the incision and suspended slightly above the level of the animal by attaching the oviduct to an immobile stand. Under a dissecting microscope, the bursal sac surrounding the ovary was opened, exposing the surface of the ovary and follicles.

Instrumentation. Intrafollicular pressure measurements were made using a Model 900 Micropressure system (W-P Instruments, New Haven, CT, USA) connected to a bevelled glass micropipette filled with $2 \mathrm{M}-\mathrm{KCl}$ (tip diameter: $10 \mu \mathrm{m}$ ). This is a zero displacement, servo-controlled pressure recording system (see Wiederhelm et al., 1964; Schroeder \& Talbot, 1982). The system was calibrated by comparing it to the responses of a conventional strain gauge (Gould Statham Instruments Inc., Hato Rey, Puerto Rico). Continuous tracings of intrafollicular pressure were made on an Omniscribe penwriter (Houston Instruments Inc., Austin, TX, USA). Continuous records of follicular diameter were made by connecting a video camera to the side-arm of the dissecting microscope $(\times 50)$ and recording the image on a VCR with freeze-frame capability. The monitor screen was calibrated with an acetate overlay constructed by viewing a stage micrometer through the video camera. Changes in antral fluid volumes were affected by either injecting or withdrawing fluid through a second glass micropipette, which was connected to a $2 \mathrm{ml}$ micrometer syringe, with $1 \mu$ l divisions (Gilmont Instruments Inc., Great Neck, NY, USA).

Experimental. While monitoring both intrafollicular pressure and follicular diameter, 1-10 1 Tyrode's solution were injected into the antrum of the follicles. The pressure tracings were matched with the videotape such that a given intrafollicular pressure could be paired exactly with a follicular diameter. Pressure and diameter data for individual follicles were used to construct approximate length-tension curves. This method of computing the length of theoretical circumferential fibres differs from those in previous reports in that continuous values of follicular diameter were available from the videotape. In previous studies, a known volume was injected into a follicle whose diameter had been previously measured (e.g. Rondell, 1970a, b; Bronson et al., 1979). Follicular wall tension in dynes $/ \mathrm{cm}$ ( 1 dyne $=10 \mu \mathrm{N}$ ) was obtained from the Laplace relationship for thin-walled spheres, in which tension $=$ (pressure) $\times$ (radius) $/ 2$. The slope of the length-tension curves was then a measure of the stiffness of the follicular wall. Passive stretch length-tension curves were generated for 2 samples of preovulatory follicles in the intervals of $1-2 \mathrm{~h}$ and $0-1 \mathrm{~h}$ before expected ovulation.

In a different set of experiments, the effect of relaxation of the follicular wall was examined. This was done by withdrawing fluid from the antrum with the microsyringe. In some experiments, $1-3$ drops of a $10^{-3} \mathrm{M}$ solution of 5-hydroxytryptamine (Sigma) were applied to the surface of the follicle, while intrafollicular pressure and follicular diameter were monitored.

Trials in which the micropressure system's warning claxon sounded for an extended period (indicating that the pipette tip was plugged or out of an aqueous environment) or in which resting intrafollicular pressure was less than atmospheric were excluded from the data set.

Numeric values are given \pm one standard error of the mean. 


\section{Results}

\section{General properties of the preparation}

Visual monitoring of hamster preovulatory follicles revealed that, as the time of ovulation approached, the follicles assumed a characteristic appearance, relative to engorgement of the capillary networks, opacity of the apex and firmness of the wall when challenged with micropipette puncture, that allowed us to predict the amount of time remaining before rupture. By comparing the appearance of these follicles to ones in which the animal was given hCG (which regularly results in ovulation $13 \mathrm{~h}$ after administration), we could classify follicles as being $<1 \mathrm{~h}$ or $1-2 \mathrm{~h}$ before ovulation.

Measurements of intrafollicular pressure in large preovulatory hamster follicles that were within $1 \mathrm{~h}$ of expected ovulation averaged $3.9 \pm 1.6 \mathrm{mmHg}(n=6)$. These follicles averaged $1.07 \pm 0.09 \mathrm{~mm}$ in diameter. Follicles between $1-2 \mathrm{~h}$ before ovulation had average diameters of $1.065 \pm 0.053 \mathrm{~mm},(n=21)$ and pressures averaging $4.2 \pm 0.7 \mathrm{mmHg}$ (see Table 1 ).

Table 1. Characteristics of hamster preovulatory follicles

\begin{tabular}{|c|c|c|}
\hline & $\begin{array}{c}0-1 \text { h before } \\
\text { ovulation }\end{array}$ & $\begin{array}{c}\text { 1-2 } \mathrm{h} \text { before } \\
\text { ovulation }\end{array}$ \\
\hline $\begin{array}{l}\text { Resting intrafollicular } \\
\text { pressure (mmHg) } \\
\text { Resting follicular } \\
\quad \text { diameter }(\mathrm{mm}) \\
\text { Wall thickness }(\mathrm{mm}) \\
\text { Stiffness }(\text { dynes } / \mathrm{cm} / \mathrm{cm}) \ddagger\end{array}$ & $\begin{array}{c}1.068 \pm 0.09 \\
0.045^{*} \\
4693 \pm 555\end{array}$ & $\begin{array}{c}1.065 \pm 0.053 \\
0.05^{*} \\
24520 \pm 2796\end{array}$ \\
\hline \multicolumn{3}{|c|}{$\begin{array}{l}\text { Values are mean and s.e.m. for } 6(0-1 \mathrm{~h}) \text { and } 21(1-2 \mathrm{~h}) \text { follicles. } \\
\text { *From Martin \& Talbot }(1987) \text { : values reflect our averaging of } \\
\text { mean basal }(n=40) \text { and apical }(n=49) \text { thickness measurements } \\
\text { reported by these workers. No variance values for wall thickness } \\
\text { means were given in this paper. } \\
+1 \mathrm{mmHg}=133 \mathrm{~Pa} \text {. } \\
+1 \text { dyne }=10 \mu \mathrm{N} \text {. }\end{array}$} \\
\hline
\end{tabular}

The extent to which capillary hydrostatic pressure maintains follicular diameter was evaluated by severing the ovarian artery while monitoring follicular diameter. Interruption of the blood supply to the ovaries always produced declines in diameter over the course of $5 \mathrm{~min}$. Diameters averaged $0.94 \pm 0.05 \mathrm{~mm}$ before severance and $0.805 \pm 0.17 \mathrm{~mm}$ after the vessels were cut, reflecting a $14.2 \%$ decrease $(n=10)$. This corresponds to a $37 \%$ reduction in volume. Since the seal around the pressure electrode is not always tight, no attempt was made to impale these follicles.

When 5-hydroxytryptamine was applied to the surface of 1-2 $\mathrm{h}$ preovulatory follicles, a contractile episode was initiated (Fig. 1). The response was usually cyclic, with alternate rises and declines in intrafollicular pressure, with a periodicity of 1 cycle every $2-3 \mathrm{sec}$. There were no concurrent volume changes during the response.

\section{Passive responses to stretch}

Injection of Tyrode's solution into the antrum of preovulatory follicles caused an increase in intrafollicular pressure and diameter, followed by a decline in both pressure and volume as the fluid was taken away with venous outflow or leaked out from around the pipette puncture sites (Fig. 2). The rate of pressure decline varied greatly in preparations and in different trials in the same 


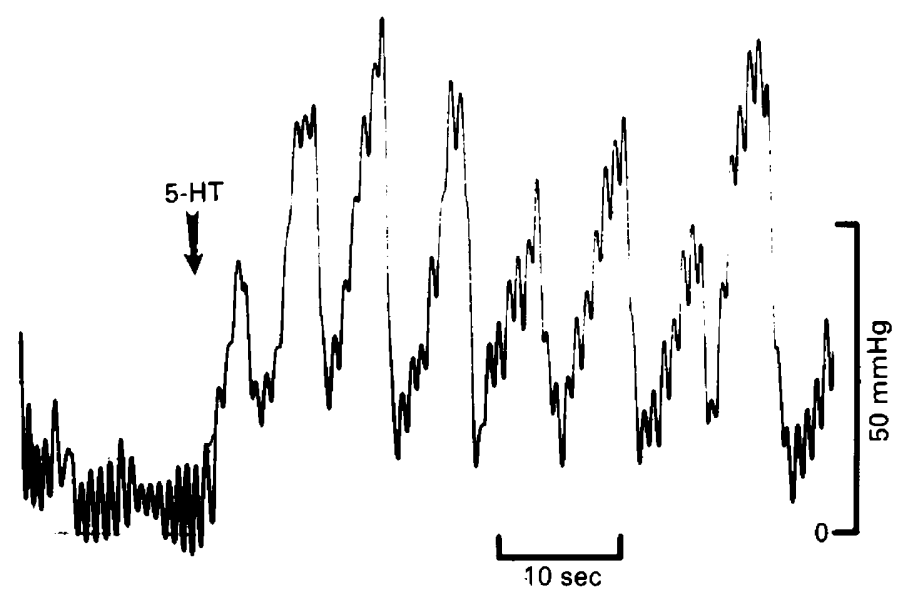

Fig. 1. Intrafollicular pressure tracing of a preovulatory follicle exposed to $10^{-3} \mathrm{M}-5$-hydroxytryptamine $(5-\mathrm{HT})$. This response may be compared to the mechanically activated responses illustrated later.

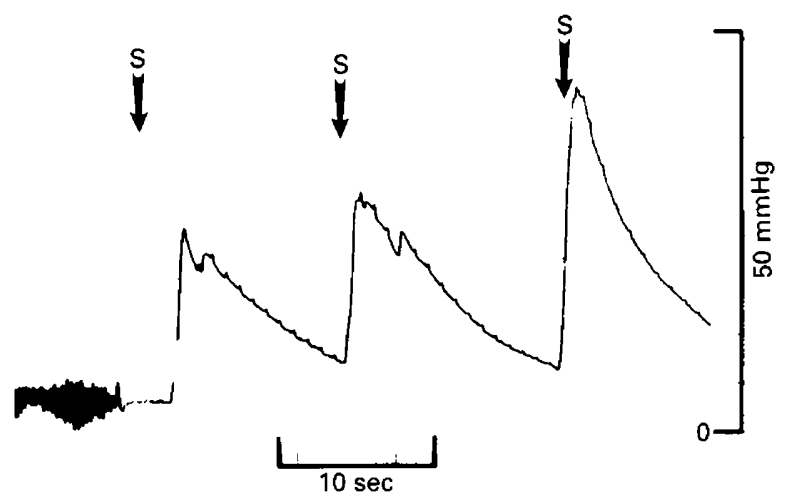

Fig. 2. Intrafollicular pressures in response to step increases of 1-5 $\mu$ l in antral volume; injections are indicated at $\mathbf{S}$. No active contraction was induced.

preparation. This rate of decline was affected by the tightness of the seal around the 2 micropipettes as well as by the peak pressure. No changes in pressure or volume ever occurred when the volume change was induced in a follicle other than the one being monitored.

Passive stretch length-tension curves were constructed from the values of intrafollicular pressure and follicular diameter before and after injection of fluid into the follicles. Tension in dynes/cm was computed from the Laplace relation for force balance of thin-walled spheres. In a sample of 21 follicles that were 1-2 h before ovulation (Fig. 3a), differences in slope of the curves between follicles were distributed around a mean of $24520 \pm 2796 \mathrm{dynes} / \mathrm{cm} / \mathrm{cm}$. Wall stiffness in the sample of follicles that were within $1 \mathrm{~h}$ of expected ovulation (Fig. 3b) was much lower, with an average slope of $4693 \pm 555 \mathrm{dynes} / \mathrm{cm} / \mathrm{cm}(n=6)$. The length-tension curves of the two samples were from different populations $(\mathrm{t}=16.3$ with $\mathrm{df}=26 ; P<0.005$; Student's $t$ test $)$. 


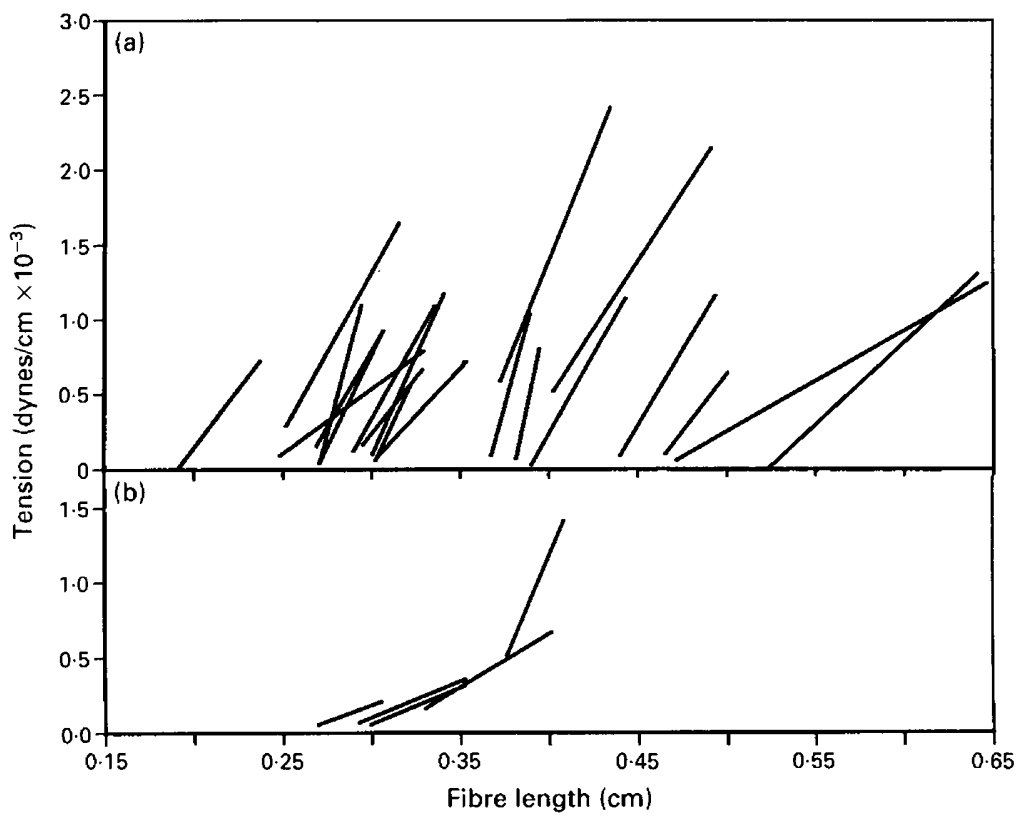

Fig. 3. Approximate passive length-tension curves for (a) 21 hamster follicles that were $1-2 \mathrm{~h}$ before ovulation and (b) 6 hamster follicles that were $<1 \mathrm{~h}$ before ovulation. Each curve was derived by taking the intrafollicular pressure and follicular diameter values at pre-injection and peak pressure times. The slopes of the curves are measures of the stiffness of the follicular wall. In (b) values for 2 of the follicles were identical and are represented with a single line.

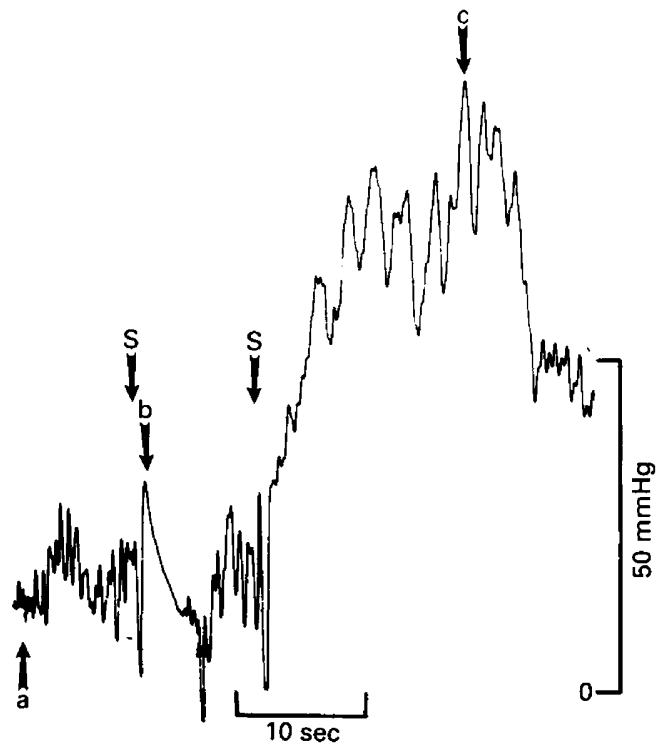

Fig. 4. Intrafollicular pressure tracing of an active response. Injection of Tyrode's solution at $\mathbf{S}$. Measurements of pressure and diameter were taken at $a, b$, and $c$. After the second injection, intrafollicular pressure increased to nearly $80 \mathrm{mmHg}$ without change in follicular diameter. 


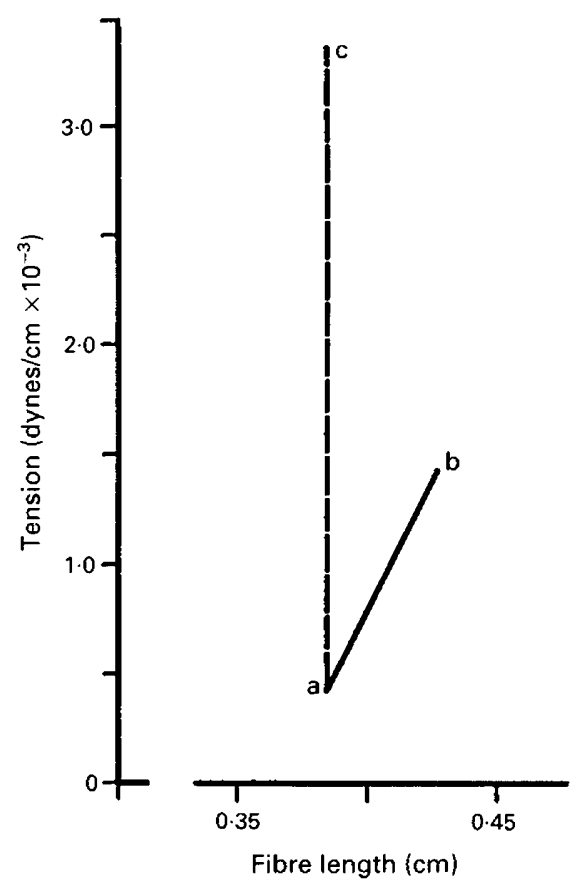

Fig. 5. Approximate passive length-tension curve for the follicle in Fig. 4. The curve was constructed from points $a$ and $b$ in Fig. 4. Point $c$ is taken from the peak of the active response.

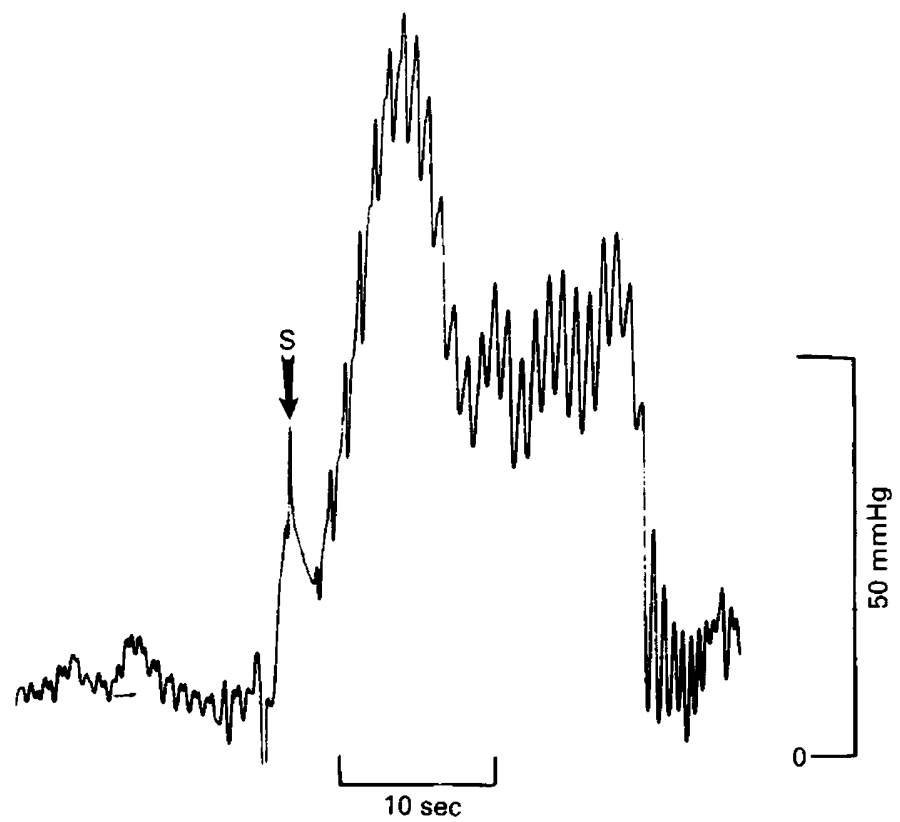

Fig. 6. Tracing of a follicular contractile response that followed an injection of fluid into the antrum (S). Note the initial rate of decay of the intrafollicular pressure compared to that in Fig. 1. 


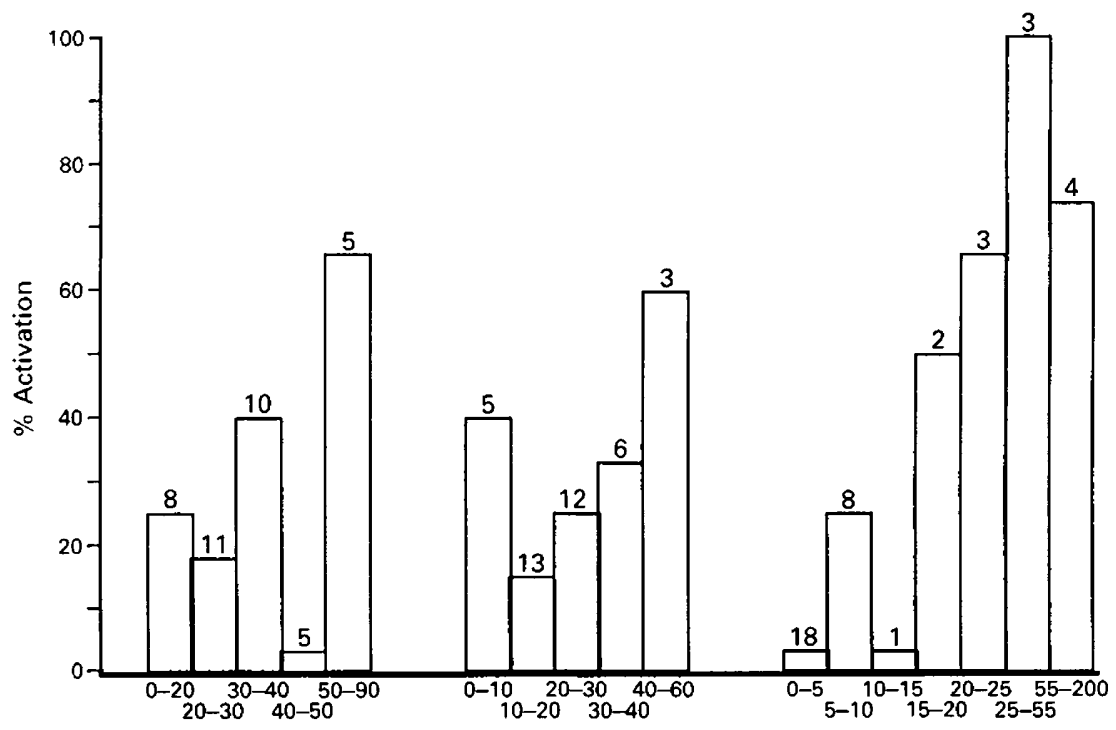

$\begin{array}{lll}\text { (a) Peak pressure }(\mathrm{mmHg}) & \text { (b) }-\mathrm{dp}(\mathrm{mmHg}) & \text { (c) }-\mathrm{dp} / \mathrm{dt}\end{array}$

Fig. 7. Histograms of the percentage of hamster follicles exhibiting an active response vs increasing magnitude of the volume perturbation when the amount of stretch is considered (a); when the amount of stretch release is considered (b); and when both the magnitude and rate of stretch release are considered (c). Numbers above the bars denote sample size in each category.

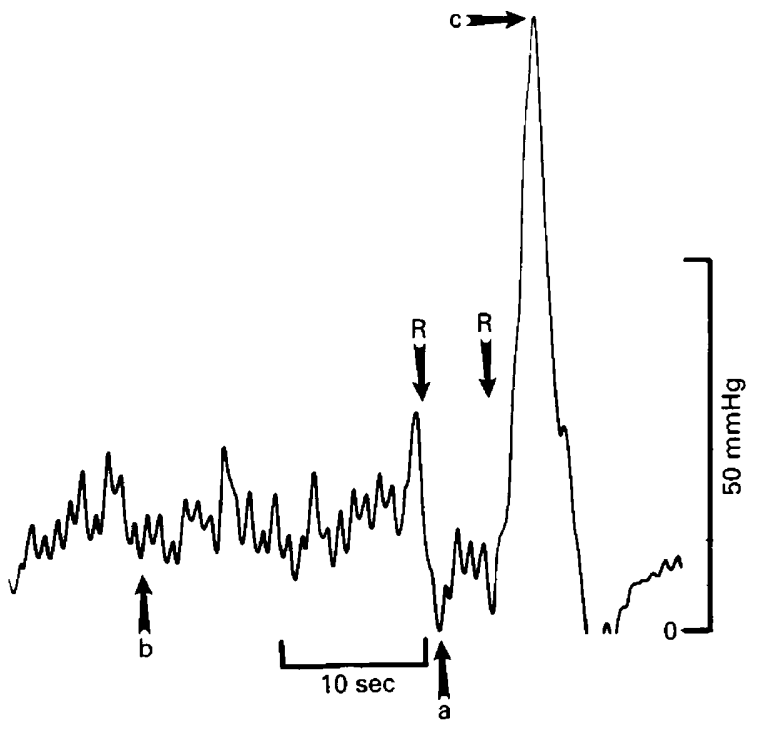

Fig. 8. Intrafollicular pressure tracing of an active response. Removal of solution at $R$. The points $a, b$, and $c$ are as in Fig. 4. 


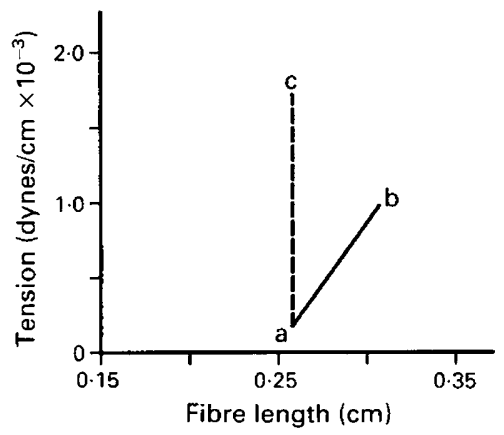

Fig. 9. Approximate passive length-tension curve for the follicle in Fig. 8. The curve was constructed from points $a$ and $b$ in Fig. 8. Point $c$ is taken from the peak of the active response.

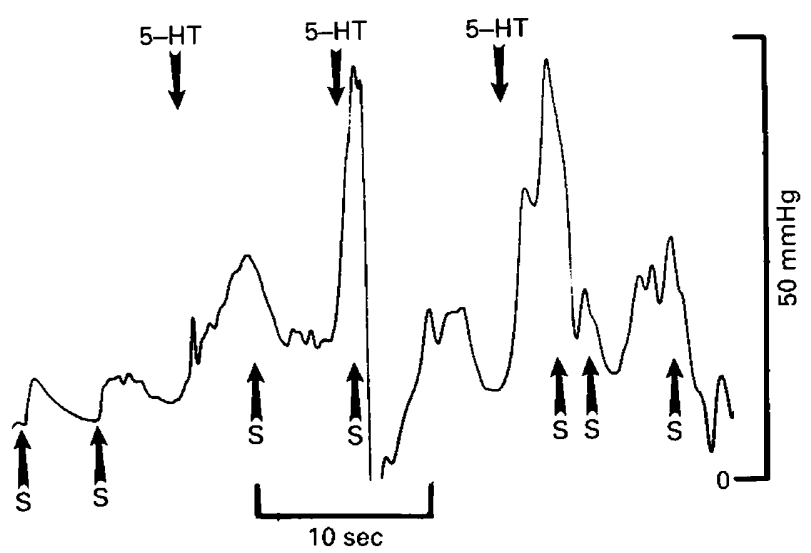

Fig. 10. Pressure tracing of a follicle that was subjected to passive stretch (S) during contractile responses to 5-hydroxytryptamine (5-HT). Each injection inhibited pharmacologically-induced tension development.

\section{Active contractile responses}

In all subsequent experiments, data collection was limited to follicles that were $1-2 \mathrm{~h}$ from ovulation. In the last hour before ovulation, the cumulus mass material, which has a gelatinous consistency, swells to a diameter approaching the dimensions of the antrum during this interval (Talbot \& DiCarlantonio, 1984). The $10 \mu \mathrm{m}$ tip of the pressure pipette almost invariably became clogged at this late time. For follicles $1-2 \mathrm{~h}$ before ovulation, computed values of wall tension were normally compared to the passive length-tension curve for the follicle being monitored. When the control values were unavailable for a particular follicle, the average stiffness value of 24520 dynes $/ \mathrm{cm} / \mathrm{cm}$ was used.

Active contraction sometimes occurred when fluid was injected into follicles in the $1-2 \mathrm{~h}$ group (Figs 4 and 6). Characteristically, there was a rise and then a fall both in intrafollicular pressure and radius, followed by a sudden increase in intrafollicular pressure lasting $30 \mathrm{sec}-2 \mathrm{~min}$ with no corresponding change in radius.

Active responses to passive stretch (Figs 4 and 6) were elicited in 11 of 39 successful recordings. Since the responses always followed the fall in pressure (and volume) after an injection, contraction 
might have been initiated by the initial stretch, the subsequent relaxation or by the rate of relaxation. We examined the correlates of these variables, i.e. peak pressure, $-\mathrm{dp}$ (the magnitude of the subsequent fall in pressure) and $-\mathrm{dp} / \mathrm{dt}$ ( $-\mathrm{dp}$ divided by the time elapsed). The 39 trials were sorted into 5 or more groups according to the magnitude of the putative independent variable and according to the natural grouping patterns of the data. The frequency of obtaining a response was then computed for each group (Fig. 7) and $\chi^{2}$ tests were used to test whether the set of frequencies was different from uniform for each independent variable. The frequencies of obtaining an active contractile response did not differ as a function of peak pressure or as a function of $-\mathrm{dp}$. However, it was a function of $-\mathrm{dp} / \mathrm{dt}\left(\chi^{2}=17 \cdot 2\right.$, with $\left.\mathrm{df}=6 ; P<0.01\right)$.

\section{Responses to fluid withdrawal}

On the basis of these results, we directly examined the possibility that removal of passive stretch was initiating the contractile response by withdrawing fluid from the antrum. Withdrawal of fluid was extremely difficult because of clogging of both pipettes with cumulus material. More than $99 \%$ of attempts resulted in the claxon sounding or the pressure falling to below atmospheric. In the remaining trials, an active contraction was triggered in 6 out of 18 cases. Figure 8 depicts pressure tracings of a follicle in which there was a decrease in passive stretch without any prior injection of fluid into the antrum; the length-tension relation is depicted in Fig. 9.

To evaluate whether these results reflected a relaxation-induced response or simply a removal of stretch inhibition, Tyrode's solution was injected into follicles that were actively responding to a previous application of 5-hydroxytryptamine. In all 9 trials, an increase in passive stretch during a 5-hydroxytryptamine-induced isometric contractile episode resulted in a decrease in intrafollicular pressure that lasted for the duration of the injection (Fig. 10). In some cases, the episode was transiently interrupted by stretch, but then continued when the follicular volume returned to resting values.

\section{Discussion}

The passive length-tension curves (Fig. 3a) for hamster preovulatory follicles $1-2 \mathrm{~h}$ before ovulation are characterized by slopes that are intermediate between those of pre-LH surge and just preovulatory follicles for the pig (Bronson et al., 1979) and rabbit (Rondell, 1970a, b). Follicles that are within $1 \mathrm{~h}$ of ovulation (Fig. 3b) exhibit slopes reflecting decreased wall stiffness. Our data are in agreement with previous reports demonstrating that follicular wall stiffness decreases with approaching ovulation (Rondell, 1970a, b; Bronson et al., 1979; Espey, 1980), presumably as a result of proteolysis of the wall matrix (Ichikawa et al., 1983a, b).

Smooth muscle in the wall of preovulatory hamster follicles is capable of generating contractile responses to mechanical and pharmacological stimuli. The intrafollicular pressure in follicles that were actively responding to a release of stretch sometimes reached $80 \mathrm{mmHg}$, which represents a wall tension of $5332 \mathrm{dynes} / \mathrm{cm}$ (for a $1 \mathrm{~mm}$ follicle). If this value is divided by a wall thickness of $0.005 \mathrm{~cm}$ (average value based on apical and basal wall measurements in the hamster reported by Martin \& Talbot, 1987), the active tension is computed to be $1.06 \times 10^{6}$ dynes $/ \mathrm{cm}^{2}$ of crosssectional area.

This value is similar to that reported for other types of smooth muscle. Values for maximum tension development in mammalian arterial smooth muscle range from $3.87 \times 10^{5}$ dynes $/ \mathrm{cm}^{2}$ for coronary artery to $2 \cdot 14 \times 10^{6}$ dynes $/ \mathrm{cm}^{2}$ for renal artery (Cox, 1984). Higher values of $10^{8}$ dynes/ $\mathrm{cm}^{2}$ have been reported by Murphy et al. (1977) for aorta, urinary bladder and uterus.

By continuously monitoring follicular diameter along with intrafollicular pressure, we were able to rule out passive stretch as the source of follicular wall tension development, since passive stretch would have required a volume change which was never observed. Increases in follicular diameter or height of the follicles were never observed during either the 5-hydroxytryptamine or the 
mechanically induced contractile episodes. Furthermore, computed tension development values during the responses were not on the passive length-tension curves (Figs 5 and 9).

Earlier reports that presented continuous tracings of intrafollicular pressure for the periods just before and during ovulation in the anaesthetized rabbit (Espey \& Lipner, 1963; Rondell, 1970a, b) and in the isolated hamster follicle (Schroeder \& Talbot, 1982) showed that intrafollicular pressure remained relatively constant or decreased slightly in the minutes before ovulation and then dropped rapidly as the follicle ruptured. However, any increase in wall tension after rupture would not result in an increase in intrafollicular pressure, as the antral fluid would have moved out through the rupture site.

In Figs 4, 6 and 8, the diameters of the follicles during the contractile episodes were the same as for the pre-stretch period. This indicates that the amount of passive stretch created by a volume injection is not, in itself, a measure of the likelihood of a contraction. Since large drops in intrafollicular pressure and follicular diameter were no more effective in triggering a response than were small changes (Fig. 7), our data do not support the idea that a contractile response can be triggered solely by decreasing the amount of stretch. The increasing probability of triggering contractile responses as $-\mathrm{dp} / \mathrm{dt}$ increased demonstrates a rate-sensitive mechanism. That the mechanism is refractory to activation until there is a rapid change in passive stretch is implied by the fact that no contractions were ever observed to occur spontaneously (even in intact follicles that had previously responded to a mechanical stimulus).

Previous in-vitro studies have shown a change in follicle shape and the appearance of a constriction at the base of the follicle during the 15 or 20 min preceding rupture. In these studies, rupture was identified as the first appearance of the cumulus mass. The stimulus for these pre-ovulatory changes was proposed to be stretch (Martin \& Talbot, 1981a, b, 1987), neurotransmitters (Talbot \& Schroeder, 1982) or both (Talbot \& Chacon, 1982). It is unfortunate that intrafollicular cumulus expansion prevented us from obtaining data during this period. Therefore, although our results are consistent both with these studies and those reporting a rapid fall of intrafollicular pressure at ovulation (see above), they tell us nothing about what is happening during this period. During the ovulatory sequence, a sudden release of passive stretch occurs when the already perforated follicle wall splits. These earlier 'microruptures' are probably plugged by the expanded cumulus mass so that intrafollicular pressure declines only slightly (Schroeder \& Talbot, 1982). The rupture permitting the appearance of the cumulus might be a response to the accumulating effects of basal contraction, cumulus expansion or continuing enzymic degradation; it allows fluid to escape rapidly, causing a precipitous drop in intrafollicular pressure (Schroeder \& Talbot, 1982). This rapid decrease in hydrostastic pressure would induce contraction of muscle in the follicle wall, which would in turn assist in complete evacuation of the follicle, a process which requires up to $10 \mathrm{~min}$ (Talbot, 1983). The contractile response initiated by follicular rupture may further function to pull the wall down on the surface of the ovary. This event would be mediated by a positive feedback mechanism such that, once contraction is initiated, continued shortening of the fibres would remove progressively more of the inhibition resulting from passive stretch. As a result, the response would tend to proceed continuously until either fibre length or actin filament compaction became limiting. Finally, passive tension in the wall before ovulation may serve to inhibit contractile responses to endogenous pharmacological agents (e.g. platelet-derived 5-hydroxytryptamine).

Mechanical activation of smooth muscle surrounding hollow organs has been well documented and is frequently mediated through stretch-gated cation channels in the cell membrane that are selective for potassium or calcium (review: Kullberg, 1987). In follicular smooth muscle, a potassium channel that exhibited increased conductance in response to stretch would function to hyperpolarize the membrane and inhibit any voltage-dependent response. Release of stretch that caused closure of such a leakage channel, would permit the membrane potential to approach threshold values. The derivative sensitivity exhibited in our preparation may reflect that, as the absolute magnitude of $-\mathrm{dp} / \mathrm{dt}$ increased, the amount of time that the tissue was under little or no passive stretch also increased, thus removing the hyperpolarizing influence for a longer period. 
We thank Marc Pellicciaro for invaluable assistance in collection of these data.

\section{References}

Bast, J.D. \& Greenwald, G.S. (1974) Serum profiles of follicle stimulating hormone, luteinizing hormone and prolactin during the estrous cycle in the hamster. Endocrinology 94, 1295-1299.

Bronson, R.A., Bryand, G., Balk, M.W. \& Emanuele, N. (1979) Intrafollicular pressure within preovulatory follicles of the pig. Fert. Steril. 31, 205-213.

Cox, R.H. (1984) Mechanics of blood vessels: conduit arteries. In Smooth Muscle Contraction, pp. 405-426. Ed. N. L. Stephens. Marcel Decker, New York.

Espey, L.L. (1980) Ovulation as an inflammatory reaction: a hypothesis. Biol. Reprod. 22, 73-106.

Espey, L.L. \& Lipner, H. (1963) Measurements of intrafollicular pressures in the rabbit ovary. Am. J. Physiol. 205, 1067-1072.

Ichikawa, S., Ohta, M., Morioka, H. \& Murao, S. (1983a) Blockage of ovulation in the explanted hamster ovary by a collagenase inhibitor. $J$. Reprod. Fert. 68, 17-19.

Ichikawa, S., Morioka, H., Ohta, M., Oda, K. \& Murao, S. (1983b) Effect of various proteinase inhibitors on ovulation of explanted hamster ovaries. J. Reprod. Fert. 68, 407-412.

Kannisto, P., Owman, Ch. \& Walles, B. (1985) Involvement of local adrenergic receptors in the process of ovulation in gonadotrophin-primed immature rats. $J$. Reprod. Fert. 75, 357-362.

Kullberg, R. (1987) Stretch-activated channels in bacteria and animal cell membranes. Trends Neurosci. 10, 387-388.

Lofman, C.O., Janson, P.O., Kallfelt, B., Ahren, K. \& LeMaire, W.J. (1982) The study of ovulation in the isolated perfused rabbit ovary. II. Photographic and cinematographic observations. Biol. Reprod. 26, 467473.

Martin, G.G. \& Talbot, P. (1981a) The role of follicular smooth muscle cells in hamster ovulation. $J$. exp. Zool. 216, 469-482.

Martin, G.G. \& Talbot, P. (1981b) Drugs that block smooth muscle contraction inhibit in vivo ovulation in hamsters. J. exp. Zool. 216, 483-491.

Martin, G.G. \& Talbot, P. (1987) Formation of the rupture site in preovulatory hamster follicles: morphological and morphometric analysis of thinning of the granulosa and thecal layers. Gamete Res. $17,303-320$.

Murphy, R.A., Driska, S.P. \& Cohen, D.M. (1977) Variations in actin to myosin ratios and cellular force generation in vertebrate smooth muscles. In Excitation-Contraction Coupling in Smooth Muscle, pp. 417-424. Eds R. Casteels, T. Goodfraind \& J.C. Ruegg. Elsevier/North-Holland, Amsterdam.

Orsini, M.W. (1961) The external vaginal phenomena characterizing the stages of the estrous cycle, pregnancy, lactation and the anestrous hamster Mesocricetus Auratus Waterhouse. Proc. Anim. Care. Panel. 11, 193-206.

Reuter, L.A., Ciaccio, L.A. \& Lisk, R.D. (1970) Progesterone: regulation of estrous cycle, ovulation and estrous behavior in the golden hamster. Endocrinology 86, 1287-1297.

Rondell, P. (1970a) Biophysical aspects of ovulation. Biol. Reprod. Suppl. 2, 6489.

Rondell, P. (1970b) Follicular processes in ovulation. Fedn Proc. Fedn Am. Socs exp. Biol. 29, 1875-1879.

Schroeder, P.C. \& Talbot, P. (1982) Intrafollicular pressure decreases in hamster preovulatory follicles during smooth muscle cell contraction in vitro. $J$. exp. Zool. 224, 417-426.

Self, D.A., Schroeder, P.C. \& Gown, A.M. (1988) Hamster thecal cells express muscle characteristics. Biol. Reprod. 39, 119-130.

Spicer, L.J. (1986) Catecholaminergic regulation of ovarian function in mammals: current concepts. Life Sci. 39, 1701-1711.

Stefanson, A., Owman, C., Sjoberg, N., Sporrong, B. \& Walles, B. (1981) Comparative study of the autonomic innervation of the mammalian ovary, with particular regard to the follicular system. Cell Tiss. Res. 215, 47-62.

Talbot, P. (1983) Videotape analysis of hamster ovulation in vitro. J. exp. Zool. 225, 141-148.

Talbot, P. \& Chacon, R.S. (1982) In vitro ovulation of hamster oocytes depends on contraction of follicular smooth muscle cells. J. exp. Zool. 224, 409-415.

Talbot, P. \& DiCarlantonio, G. (1984) Architecture of the hamster oocyte-cumulus complex. Gamete Res. 9, 261-272.

Talbot, P. \& Schroeder, P.C. (1982) 5-hydroxytryptamine causes contraction of smooth muscle cells in preovulatory hamster follicles. J. exp. Zool. 224, $427-436$.

Wiederhelm, C.A., Woodbury, J.W., Kirk, S. \& Rushmer, R.F. (1964) Pulsatile pressures in the microcirculation of frog's mesentery. Am. J. Physiol. 207, 173-176.

Wylie, S.N., Roche, P.J. \& Gibson, W.R. (1985) Ovulation after sympathetic denervation of the rat ovary produced by freezing its nerve supply. J. Reprod. Fert. 75, 369-373. 